\title{
Een contextgebonden training voor huisartsen in communicatieve vaardigheden bij lageluchtweginfecties*
}

\author{
J.W.L. Cals, N.A.M. Scheppers, R.M. Hopstaken, K. Hood, G-J Dinant, H. Goettsch, C.C. Butler
}

\section{Samenvatting}

Doel: Bepalen of een trainingsprogramma ter bevordering van de communicatieve vaardigheden van huisartsen bij lageluchtweginfecties, resulteert in de verwerving en handhaving van deze vaardigheden zonder de duur van het consult te verlengen. Het programma bestond uit contextgebonden leerervaringen en 'peer review' van transcripten van simulatiepatiëntconsulten in de eigen praktijk.

Methoden: Een 'pre-test-post-test'-evaluatie van de training in communicatieve vaardigheden van 20 huisartsen. Transcripten van simulatiepatiëntconsulten vóór, direct en zes maanden na een trainingseminar werden geanalyseerd en vergeleken. Om de competentie van de huisartsen in het toepassen van de vaardigheden te toetsen, werden de transcripten gescoord op specifieke items.

Resultaten: Na de training pasten de huisartsen de communicatieve vaardigheden toe en deze vaardigheden bleven behouden op de lange termijn zonder dat de consultduur beïnvloed werd. Discussie en conclusie: Een grotendeels contextgebonden communicatietraining, met de mogelijkheid deze vaardigheden te oefenen met simulatiepatiënten tijdens het spreekuur en zonder beïnvloeding van de consultduur, stellen huisartsen in staat specifieke communicatieve vaardigheden voor lageluchtweginfecties succesvol toe te passen. Een uniek kenmerk van de training was het geven en ontvangen van feedback op de transcripten (peer review) van de simulatiepatiëntconsulten. (Cals JWL, Scheppers NAM, Hopstaken RM, Hood K, Dinant G-J, Goetssch H, Butler CC. Een contextgebonden training voor huisartsen in communicatieve vaardigheden bij lageluchtweginfecties. Tijdschrift voor Medisch Onderwijs 2008;27(3):137-146.)

\section{Inleiding}

Het onnodig voorschrijven van antibiotica in de huisartsenpraktijk is in een tijdperk van toenemende bacteriële resistentie een belangrijke bedreiging van de volksgezondheid. ${ }^{1}$ Onnodige voorschriften komen veel voor bij de behandeling van lageluchtweginfecties (LLWI). In ca $80 \%$ van de gevallen wordt een recept voor antibiotica uitgeschreven en dit ondanks de bewijzen van het zeer beperkte nut hiervan voor de patiënt. ${ }^{2-3}$ Huisartsen zijn zich bewust van het feit dat zij teveel antibiotica voorschrijven voor acute bronchitis, de meest voorkomende LLWI. ${ }^{4}$ Enerzijds spelen onzekerheid over de door hen gestelde

\footnotetext{
Dit artikel verscheen eerder onder de oorspronkelijk titel: Cals J.W.L., Scheppers N.A.M., Hopstaken R.M., Hood K., Dinant G-J, Goettsch H. and Butler C.C. Evidence based management of acute bronchitis; sustained competence of enhanced communication skills acquisition in general practice. Patient Education and Counseling 2007;68:270-278.
} 
diagnose en anderzijds niet-klinische factoren, zoals tijdsdruk, aannames omtrent de verwachtingen van de patiënt en de wens om een goede arts-patiëntrelatie te onderhouden, een belangrijke rol bij het besluit toch antibiotica voor te schrijven. ${ }^{5-6}$

$\mathrm{Bij}$ het streven naar optimale medische zorg is een goede communicatie tussen arts en patiënt een essentiële factor. Bij patiënten met acute bronchitis moeten huisartsen over communicatieve vaardigheden beschikken die hen in staat stellen ook in te gaan op niet-medische invloeden. Zij moeten niet alleen de 'agenda' van de patiënt doorzien en hierop reageren, maar ook realistische verwachtingen scheppen omtrent het natuurlijk beloop en de voor- en nadelen van een behandeling met antibiotica inschatten. Verder dienen zij aan te geven wat de patiënt zelf kan doen (zelfmanagement) en wanneer een vervolgconsult wenselijk is. Het trainen van huisartsen in communicatieve vaardigheden die gericht zijn op bovenstaande zaken, kan leiden tot een hogere kwaliteit van de consulten.

Rollnick ontwikkelde een innovatieve training in communicatieve vaardigheden die aangetoond heeft praktisch en aanvaardbaar te zijn voor ervaren artsen.7-8 Deze training hebben we verder ontwikkeld en toegespitst op het trainen van huisartsen in communicatieve vaardigheden tijdens consulten voor LLWI. Alhoewel het aannemelijk is dat huisartsen op de korte termijn een verbeterde bekwaamheid kunnen laten zien, is het voor het handelen in de dagelijkse praktijk op de lange termijn noodzakelijk dat vastgesteld wordt of deze bekwaamheid wordt behouden. ${ }^{9}$ Deze studie heeft tot doel te bepalen of huisartsen die getraind worden in het verbeteren van hun communicatieve vaardigheden, deze kunnen toepassen in de dagelijkse praktijk, en in welke mate zij op de langere termijn deze verworven vaardigheden kunnen behouden.

\section{Methoden}

\section{Onderzoeksdesign en deelnemers}

Voor dit onderzoek gebruikten we een 'pre-test-post-test'-model waarmee de training in communicatieve vaardigheden van 20 huisartsen werd geëvalueerd. De huisartsen maken deel uit van de IMPACT $^{3}$ studie (ISRCTN85154857) die momenteel patiënten werft voor een gecontroleerd onderzoek naar het effect van twee interventies op LLWI-management. ${ }^{10}$ Het deel van de studie dat in dit artikel wordt beschreven richt zich primair op de verwerving van vaardigheden door huisartsen. We maakten hierbij gebruik van een contextgebonden benadering met 'peer-review' van de transcripten van consulten met simulatiepatiënten. De huisartsen doorliepen de volgende trainingsonderdelen:

- Simulatiepatiëntconsult 1; in de eigen praktijk tijdens een regulier spreekuur in de week vóór de trainingsbijeenkomst met transcript 1 als resultaat (T1).

- Trainingsbijeenkomst; het bespreken van de transcripten (T1) en een introductie op de methode om de communicatieve vaardigheden bij acute bronchitis te verbeteren.

- Simulatiepatiëntconsult 2; binnen twee weken na de training (T2).

- Het geven van feedback ('peer review') op transcript T2 van een collega, alsmede het ontvangen van feedback op het eigen transcript.

- Simulatiepatiëntconsult 3; een half jaar na de training (T3).

De consulten met de tweede en derde simulatiepatiënt boden de mogelijkheid de verworven vaardigheden te oefenen, maar werden door ons ook gebruikt om de verworven vaardigheden te evalueren. 


\section{Simulatiepatiëntconsulten}

Drie simulatiepatienten werden getraind in de rol van een patiënt met acute bronchitis. Allen hadden minimaal tien jaar ervaring in het spelen van rollen als simulatiepatiënt op het skillslab van de Universiteit van Maastricht. Zij ontvingen tijdens een trainingssessie met de onderzoekers uitgebreide schriftelijke informatie over het klinische scenario en hun rol. De huisartsen waren geïnformeerd over het feit dat een simulatiepatiënt hen zou consulteren tijdens het spreekuur, maar zij werden niet van de exacte datum of het tijdstip op de hoogte gesteld. Het scenario was gelijk bij de drie simulatieconsulten, alleen de simulatiepatiënt wisselde. De bevindingen bij lichamelijk onderzoek werden schriftelijk vastgelegd. De bandopnames van de simulatieconsulten werden uitgetypt en de tijdsduur van de consulten werd geregistreerd.

\section{De trainingsbijeenkomst}

Er werden drie centrale bijeenkomsten gehouden van twee uur met dezelfde vorm en inhoud voor vijf tot acht huisartsen per seminar. De trainingsbijeenkomst ter verbetering van de communicatieve vaardigheden was gebaseerd op een strategie waarbij de patiënt centraal staat met als doel het bereiken van een overeenkomst omtrent het onderzoek en behandeling van acute infecties. ${ }^{11}$ De inhoud van de training was gestructureerd rond het 'elicit-provide-elicit framework' voor efficiënte informatieuitwisseling, welke ontleend is aan 'health behavioral counseling'. ${ }^{12}$ De inhoud van de training is in een eerder artikel uitgebreid beschreven. ${ }^{13}$

Een gedragswetenschapper van de huisartsopleiding leidde de bijeenkomsten. $\mathrm{Na}$ een korte introductie kregen de huisartsen het eerste simulatiepatiënttranscript. Belangrijke aspecten en moeilijkheden met acute bronchitisconsulten werden be- sproken. Daarna volgde de beschrijving van de opzet van de 'elicit-provide-elicit'methode; hierbij probeert de huisarts te bepalen wat de patiënt weet over diens aandoening en wat diens belangrijkste zorgen en verwachtingen zijn. Belangrijk is dat de huisarts actief vraagt naar de mening van de patiënt over antibiotica. Het doel hiervan is tweeledig; ten eerste brengt het de kennis en de verwachtingen van de patiënt aan het licht en ten tweede geeft het de huisarts de mogelijkheid openlijk de mogelijke voor- en nadelen van een behandeling met antibiotica te bespreken. De huisarts geeft daarna relevante informatie, afhankelijk van de individuele kennis en interesse van de patiënt, en bespreekt de implicaties voor de patiënt inzake diens hulpvraag. Hij of zij geeft hierbij tevens aan bij welke alarmerende symptomen de patiënt moet terugkomen voor een consult. Als laatste probeert de huisarts te bepalen wat de interpretatie van de patiënt is van wat er in het consult is gedaan en besproken.

Om het belang van de kwaliteitsverbetering van LLWI-consulten te benadrukken, gaven we het contrast aan tussen de wetenschappelijke basis met de huidige internationale richtlijnen voor LLWI ${ }^{2-3}$ en de dagelijkse praktijk. Aan de hand van video-opnames werd de benadering toegelicht.

\section{Feedback op transcripten}

In de week die volgde op de trainingsbijeenkomst kwam de tweede simulatiepatiënt op het spreekuur. Vervolgens werd aan de huisartsen gevraagd een anoniem transcript van één van de collegae van commentaar te voorzien en suggesties aan te dragen voor verbetering. Alle deelnemende huisartsen traden op als beoordelaar en ontvingen op hun beurt feedback van een collega. 


\section{Scorelijst}

We ontwikkelden een schaal om het gebruik van de vaardigheden te toetsen. Vijf algemene communicatieve en zes specifieke LLWI-communicatie-items werden gedefinieërd. Elk onderdeel werd gewaardeerd op een schaalverdeling van vier punten, oplopend van 0 tot 3 (tabel 1). Enkele pilots werden uitgevoerd, wat resulteerde in het herzien van enkele onderdelen en van de handleiding. Uiteindelijk bekeken twee beoordelaars onafhankelijk van el- kaar dezelfde vier willekeurig uitgekozen transcripten. Hierbij werd een gemiddelde overeenkomst van $93.2 \%$ op de verschillende onderdelen gevonden alsmede een Cohen's kappa van 0.91 op de totale score. Hierna werd overgegaan tot de definitieve beoordeling van de transcripten.

Voor deze beoordeling scoorden de twee onderzoekers onafhankelijk de 60 transcripten in willekeurige volgorde (T1, T2 of T3). Wanneer de scores niet overeenkwamen, werd het verschil besproken. Bij blij-

Tabel 1. Lijst van alle communicatie-items, gebaseerd op de contextrijke communicatietraining.

Tabel 1. Lijst van alle communicatie-items, gebaseerd op de contextrijke communicatietraining.

overeenkomst kappa $(\kappa)^{*}$

\section{Algemene communicatievaardigheden}

De huisarts:

1. exploreert de zorgen van de patiënt over de hoest

2. exploreert de verwachtingen van de patiënt

3. vat het consult samen

4. controleert of de patiënt de informatie heeft begrepen

$96.7 \quad 0.92$

5. bereikt overeenkomst met de patiënt over het afgesproken beleid

\section{LLWI specifieke communicatievaardigheden}

De huisarts:

6. vraagt de patiënt actief naar diens mening over antibiotica

7. noemt de verwachte duur van de hoestklachten

8. vertelt dat de patiënt zelf in staat is te herstellen van de klachten

9. noemt zowel werking als bijwerking van antibiotica bij LLWI

10. noemt zelfzorg maatregelen (bijvoorbeeld rust nemen)

$90.0 \quad 0.80$

11. noemt bij welke alarmsymptomen de patiënt terug dient te komen

\section{Score opties}

$0=$ De vaardigheid is afwezig

$1=\mathrm{Er}$ is een minimale poging gedaan om de vaardigheid toe te passen

$2=$ De vaardigheid is toegepast

3 = De vaardigheid is uitstekend toegepast

* Om de $k$ te bepalen werd de vierpuntsschaal vereenvoudigd tot een meetschaal die zich primair richtte op aangetoond verworven vaardigheden, waarbij een score van 0 tot 1 werd beschouwd als geen bewijs voor verworven vaardigheden en score 2 tot 3 werd beschouwd als bewijs voor verworven vaardigheden.

** Vaardigheid was afwezig in alle transcripten (score 0 of 1). Cohen's kappa kon derhalve voor dit item niet worden berekend. 
vende meningsverschillen over de definitieve score, was een derde 'blinde' onderzoeker beschikbaar die de definitieve score voor het betreffende onderdeel bepaalde. De definitieve scores per onderdeel ( $0,1,2$ of 3 punten) werden daarna samengevoegd tot een totale score op de lijst en op de twee deellijsten: de algemene en de LLWI-specifieke communicatieitems (tabel 1).

De primaire uitkomst was de door de huisartsen verworven bekwaamheid op de korte- en langetermijn in het toepassen van alle communicatie-items. Secundaire uitkomsten waren de bekwaamheid op korte- en langetermijn in het toepassen van enerzijds de LLWI-specifieke communicatie-items en anderzijds van de algemene communicatie-items. Daarnaast keken we naar de duur van de consulten.
De transcripten voorafgaand aan de training werden beschouwd als het uitgangspunt en de scores van deze transcripten (T1) werden vergeleken met de scores kort (T2) en zes maanden (T3) na de trainingsbijeenkomst.

\section{Statistische analyses}

De overeenstemming tussen de twee beoordelaars werd berekend door het bepalen van de mate van overeenstemming $(\%)$ en door de toepassing van Cohen's kappa (к).

De totale scores voor de complete lijst en voor de twee deellijsten in de uitgangssituatie, zowel op korte als op lange termijn, werden met elkaar vergeleken met de test van Wilcoxon. Deze test werd ook gebruikt om het effect van de communicatietraining op de consultduur in te schatten.

Tabel 2. Gemiddelde en mediane scores, consultatietijd en veranderingen in mediane scores voor de totale lijst (alle communicatie-items) en de twee deellijsten (algemene communicatie-items en LLWI specifieke communicatie-items) alsmede gemiddelde consultatietijd in de uitgangssituatie (T1), op korte termijn (T2) en op lange termijn (T3) met Wilcoxon's signed ranks test.

\begin{tabular}{|c|c|c|c|c|c|c|c|c|}
\hline & \multicolumn{3}{|c|}{ Gemiddelde \pm SD } & \multicolumn{2}{|c|}{ Mediaan } & \multirow{2}{*}{$\begin{array}{c}\text { p-waarde } \\
\text { T1:T2 }\end{array}$} & \multirow{2}{*}{\begin{tabular}{|c|} 
Mediaan \\
T3
\end{tabular}} & \multirow{2}{*}{$\begin{array}{c}\text { p-waarde } \\
\text { T1:T3 }\end{array}$} \\
\hline & $\mathrm{T} 1$ & T2 & T3 & $\mathrm{T} 1$ & $\mathrm{~T} 2$ & & & \\
\hline $\begin{array}{l}\text { Alle communicatie-items } \\
\text { Maximale score } 33^{*}\end{array}$ & $6.90 \pm 4.34$ & $22.30 \pm 3.57$ & $18.40 \pm 4.71$ & 7.50 & 22.00 & $<0.001$ & 20.00 & $<0.001$ \\
\hline $\begin{array}{l}\text { Algemene } \\
\text { communicatie-items } \\
\text { Maximale score } 15^{*}\end{array}$ & $3.85 \pm 2.70$ & $8.45 \pm 2.91$ & $7.00 \pm 3.11$ & 3.50 & 9.00 & $<0.001$ & 8.50 & 0.001 \\
\hline $\begin{array}{l}\text { LLWI specifieke- } \\
\text { communicatie-items } \\
\text { Maximale score } 18^{*}\end{array}$ & $3.00 \pm 2.10$ & $12.95 \pm 3.10$ & $11.40 \pm 3.10$ & 3.00 & 13.00 & $<0.001$ & 11.50 & $<0.001$ \\
\hline $\begin{array}{l}\text { Duur van het consult } \\
\text { Seconden }\end{array}$ & $469 \pm 108$ & $517 \pm 98$ & $506 \pm 111$ & 444 & 504 & .064 & 483 & .073 \\
\hline
\end{tabular}

* scores per item zoals beschreven in tabel 1; minimum score $=0$; maximum score per item $=3$. 


\section{Resultaten}

Alle 20 huisartsen werden door drie simulatiepatiënten bezocht, wat resulteerde in 60 bruikbare transcripten. Twee huisartsen werden twee keer door dezelfde simulatiepatiënt bezocht, de overige 18 werden door drie verschillende simulatiepatiënten geconsulteerd. De gemiddelde leeftijd van de huisartsen was 46.0 jaar (SD 7.3), zij hadden een gemiddelde totale klinische ervaring van 19.7 jaar (SD 6.9) en hun gemiddelde ervaring als huisarts was 14.6 jaar (SD 8.2). Er waren negen vrouwelijke huisartsen.

Tabel 1 laat de overeenstemming tussen de beoordelaars per onderdeel zien in percentages variërend van $86.7 \%$ tot $98.3 \%$, alsmede de overeenstemming waarbij de mogelijkheid van toeval in de berekening werd meegenomen, variërend van $\mathrm{k}=0.73$ tot 0.92 . Voor onderdeel 3 (de samenvatting) kon $\mathrm{k}$ niet berekend worden aangezien deze vaardigheid ontbrak in alle 60 transcripten.

Tabel 2 laat de gemiddelde en mediane scores zien voor de totale lijst en voor de twee deellijsten in de uitgangssituatie (T1), op korte termijn (T2) en op lange termijn (T3). Vergeleken met de uitgangssituatie brachten de huisartsen significant meer communicatieve vaardigheden in praktijk, zowel op de korte termijn (mediane score 22.00 versus $7.50, \mathrm{p}<0.001$ ) als op de lange termijn (mediane score 20.00 versus $7.50, \mathrm{p}<0.001$ ). De algemene communicatieve vaardigheden en de LLWI-specifieke vaardigheden lieten beide een verbetering zien op zowel de korte als de lange termijn. Veranderingen in de gemiddelde consultduur waren niet statistisch significant.

Tabel 3 geeft de individuele onderdelen weer met een verbetering op zowel de korte als de lange termijn ten opzichte van de uitgangssituatie.
Tabel 3. Veranderingen in de competentie per communicatie-item op de korte termijn ten opzichte van de uitgangssituatie (T1:T2) en op de lange termijn ten opzichte van de uitgangssituatie (T1:T3).

\begin{tabular}{lcc}
\hline Communicatievaardigheid & T1:T2 & T1:T3 \\
\hline Algemene communicatie-items & & \\
1. Zorgen & $+^{*}$ & $+^{*}$ \\
2. Verwachtingen & $+^{* *}$ & $+^{*}$ \\
3. Samenvatten & & \\
4. Begrip controleren & $+^{*}$ & \\
5. Akkoord bereiken & $+^{*}$ & \\
LLWI specifieke communicatie-items & & \\
6. Mening over antibiotica & $+^{*}$ & $+^{*}$ \\
7. Duur van hoestklachten & $+^{* *}$ & $+^{* *}$ \\
8. Zelf herstellen & $+^{* *}$ & $+^{*}$ \\
9. (Bij)werkingen antibiotica & $+^{* *}$ & $+^{*}$ \\
10. Zelfzorgstrategieën & $+^{* *}$ & $+^{* *}$ \\
11. Alarmsymptomen & $+^{*}$ & $+^{*}$ \\
\hline
\end{tabular}

* $\quad \mathrm{p}<0.05$

** $\quad p<0.001$

\section{Discussie}

\section{Belangrijkste bevindingen}

In deze studie toonden we aan dat huisartsen hun communicatieve vaardigheden met betrekking tot lageluchtweginfecties op de korte en de lange termijn kunnen verbeteren door een ziektespecifieke communicatietraining te volgen. Belangrijke aspecten van het trainingsprogramma waren de beknoptheid van de workshop, het contextrijke karakter (veelal plaatsvindend in de eigen praktijk) en het vernieuwend gebruik van 'peer-review' van transcripten door (collega)huisartsen. Onze interventie had geen negatief effect op de consultduur. 


\section{Vergelijking met bestaande literatuur}

Belangrijke criteria bij de selectie van de geschikte speerpunten van een communicatietraining zijn de frequentie waarin het specifieke probleem voorkomt in de dagelijkse praktijk en de mate waarin artsen het nut inzien van het verbeteren van hun communicatieve vaardigheden voor dat klinisch probleem. ${ }^{14}$ Voor lageluchtweginfecties kan het eerste eenvoudig worden aangetoond door continue morbiditeitsregistratie, ${ }^{15}$ en in de afgelopen jaren is het nut van goede communicatie steeds duidelijker geworden. ${ }^{16}$

Communicatietraining is bewezen effectief in het veranderen van het gedrag van huisartsen op de korte termijn. Hierbij moet echter worden aangetekend dat het merendeel van het ondersteunende bewijs afkomstig is van studies met studenten en met minder ervaren artsen. ${ }^{17}$ Wanneer artsen eenmaal praktijk voeren, krijgen ze nog maar zelden een specifieke training in het verbeteren van hun communicatieve vaardigheden. ${ }^{18}$ Naar ons weten heeft geen eerdere communicatietraining voor huisartsen op zowel de korte als de lange termijn effect gehad.

Opvallend is dat ondanks het feit dat samenvatten één van de communicatieve basisvaardigheden is die studenten tijdens de studie geneeskunde geleerd wordt, we geen bewijs vonden dat deze vaardigheid werd toegepast door de huisartsen, noch in de uitgangssituatie, noch in de vervolgconsulten. Deze vaardigheid was wel één van de algemene communicatie-items waarop tijdens de training de nadruk was gelegd. Een eerder onderzoek naar het verwerven van communicatieve vaardigheden in een postdoctorale training liet een kleine verbetering van deze vaardigheid zien tijdens de training, maar in het algemeen toonden de huisartsen geen verbetering van communicatieve vaardigheden. ${ }^{19}$
In onze studie probeerden wij een contextrijke training te ontwikkelen met de uitdagingen van LLWI-consulten op de voorgrond en het verbeteren van de algemene communicatieve vaardigheden op de achtergrond. Doel hierbij was het verbeteren van zowel de specifieke als de algemene communicatieve vaardigheden. Deze benadering kan de reden zijn dat de huisartsen een verbetering lieten zien in de communicatie in algemene zin en op ziektespecifieke-items. Opvallend is wel dat op de lange termijn de ziektespecifiekeitems beter toegepast werden dan de algemene communicatie-items.

\section{Sterke en zwakke punten}

Een belangrijk deel van de training, het oefenen van de vaardigheden met simulatiepatiënten, vond plaats in de eigen huisartsenpraktijk tijdens het reguliere spreekuur. Een belangrijke component van de training en beoordeling werd dus uitgevoerd in een klinische context. In hoeverre deze interventie contextgebonden genoemd moet worden hangt af van de definitie die men hieraan geeft. Rollnick et al. beschrijft de belangrijkste kenmerken van een contextgebonden training:

- De training vindt plaats in de praktijk.

- Simulatiepatiënten met een rol die goed aansluit op zelfgedefinieerde leerdoelen.

- Transcripten van simulatiepatiëntcontacten worden bekeken met collega-artsen.

- Het gesimuleerde consult wordt herhaald. Deze cyclus kan worden herhaald in overeenstemming met de leerdoelen en de beschikbare middelen.

- Cruciaal is dat de dagelijkse klinische problemen op de voorgrond blijven, waarbij de algemene communicatieve vaardigheden slechts gezien worden als een middel om met deze problemen om te gaan. ${ }^{7}$ 
Deze contextgebonden benadering staat in contrast met het leren van communicatieve vaardigheden in een rollenspel buiten de klinische praktijk. Hierbij wordt vaak gebruik gemaakt van statische scenario's die door een trainer zijn ontwikkeld. Volgens deze definitie kan onze training zeker beschouwd worden als contextgebonden. Echter, onze trainingsbijeenkomst vond niet plaats in de praktijk en het scenario werd niet aangepast aan de hand van de discussie. Men kan daarom aanvoeren dat onze interventie niet geheel contextgebonden was. Daarom beschrijven wij onze interventie als contextrijk.

Het lezen en beoordelen van de transcripten van de gesimuleerde consulten van collega-huisartsen en het ontvangen van feedback op hun eigen beoordeelde transcript leverden voor de huisartsen aanvullende leermomenten op. Zover wij weten is dit de eerste maal dat een dergelijke 'peer review' van consulttranscripten geëvalueerd is als onderdeel van een communicatietraining. Wij zijn niet in staat het effect van de verschillende componenten van onze interventie los van elkaar te bekijken. Mocht blijken dat deze interventie effect heeft op het reduceren van de hoeveelheid voorgeschreven antibiotica dan zal een kwalitatieve evaluatie plaatsvinden van de ervaringen van de huisartsen met de verschillende componenten van de interventie.

Met als uitgangspunt een communicatietraining die relevant is voor de dagelijkse praktijk van huisartsen werden algemene communicatie-items met ziektespecifieke communicatie-items gecombineerd. Daarom kozen we ervoor een meetinstrument te ontwikkelen om in te schatten welke vaardigheden als belangrijkste werden beschouwd in LLWI-consulten. We gebruikten derhalve geen gepubliceerde meetschaal voor 'patient centred' communicatie (zoals de OPTION schaal), aangezien onze belang- rijkste focus niet specifiek gericht was op het centraal stellen van de 'patient centeredness'. Bij het interpreteren van de resultaten dient hier rekening mee te worden gehouden. Echter, we zijn wel van mening dat de LLWI-specifieke vaardigheden bruikbare hulpmiddelen zijn in het bereiken van 'patiënt centeredness' in deze consulten.

Hoewel aangenomen wordt dat een effectief trainingsprogramma ter verbetering van de communicatieve vaardigheden een minimale duur van één dag moet hebben, ${ }^{17}$ hebben wij aangetoond dat ons kortere programma effectief is voor het verbeteren van vaardigheden. We hebben overwogen gebruik te maken van onaangekondigde, incognito simulatiepatiënten, ${ }^{20}$ maar dit bleek onpraktisch voor de standaardisatie en de dataverzameling (bandopnamen), aangezien de eerste twee ontmoetingen zowel werden gebruikt om de vaardigheden te oefenen alsook om de verwerving van deze vaardigheden te evalueren. Hoewel we in staat waren het effect op de competentie aan te tonen over een periode van zes maanden, blijft er onzekerheid bestaan over de duurzaamheid van deze competentie op de langere termijn.

In deze studie hebben we de bekwaamheid (competence) van huisartsen getoetst, niet de daadwerkelijke toepassing ervan in de dagelijkse praktijk bij reguliere patiënten (het feitelijk handelen of performance). Beoordelingen op basis van een getoonde vaardigheid meten wat artsen kunnen doen in gecontroleerde situaties in de praktijk; beoordelingen op basis van het feitelijk handelen meten wat artsen daadwerkelijk doen in de praktijk. ${ }^{9}$ Het bezitten van een vaardigheid is dus een voorwaarde voor het feitelijk kunnen handelen in de praktijk. Aangezien de interventie grotendeels plaatsvond in de huisartsenpraktijk en acute bronchitis een veelvoorkomend probleem is in de huisartsenpraktijk, liggen in deze studie de verworven vaardigheid 
en het feitelijk handelen dicht bijelkaar. Echter, 'echte' patiënten vertonen allen verschillend gedrag. Duurzame implementatie van de verworven vaardigheden in verschillende situaties in de dagelijkse praktijk is een uitdaging die om verdere evaluatie vraagt.

\section{Conclusie}

Deze studie toont aan dat specifieke communicatieve vaardigheden voor lageluchtweginfecties succesvol kunnen worden toegepast door huisartsen, via een grotendeels contextgebonden communicatietraining en zonder dat de consultduur hierdoor wordt beïnvloed. Een uniek kenmerk van de training was het geven en ontvangen van feedback op de transcripten (peer review) van de simulatiepatiëntconsulten.

\section{Dankwoord}

We danken Prof. Steven Rollnick voor zijn hulp bij het ontwikkelen van de training. Verder zijn we dank verschuldigd aan de simulatiepatiënten van het skillslab van de Universiteit Maastricht, de typistes en de deelnemende huisartsen voor hun geweldige inzet bij dit project. We bedanken Birgit Berk voor haar uitvoerige hulp bij de vertaling.

\section{Literatuur}

1. Nordberg P, Monnet DL, Cars O. Antibacterial drug resistance: options for concerted action. Geneva; 2005 february 2005.

2. Smucny J, Fahey T, Becker L, Glazier R. Antibiotics for acute bronchitis. Cochrane Database Syst Rev. 2004(4)

3. Verheij TJM, Salomé PL, Bindels PJ, Chavannes AW, Ponsioen BP, Sachs APE et al. NHG-Standaard Acuut hoesten. [Dutch College of General Practitioners Guidelines on Acute Cough]. Huisarts Wet. 2003;46(9):496-506.

4. Butler CC, Rollnick S, Pill R, Maggs Rapport F, Stott N. Understanding the culture of prescribing: qualitative study of general practitioners' and patients' perceptions of antibiotics for sore throats. BMJ 1998:317(7159):637-42.
5. Butler CC, Rollnick S, Kinnersley P, Jones A, Stott N. Reducing antibiotics for respiratory tract symptoms in primary care: consolidating 'why' and considering 'how'. Br J Gen Pract 1998;48 (437):1865-70.

6. Coenen S, Michiels B, Renard D, Denekens J, Royen $\mathrm{P}$ van. Antibiotic prescribing for acute cough: the effect of perceived patient demand. $\mathrm{Br}$ J Gen Pract 2006;56(524):183-90.

7. Rollnick S, Kinnersley P, Butler C. Context-bound communication skills training: development of a new method. Med Educ 2002;36(4):377-83.

8. Rollnick S, Seale C, Kinnersley P, Rees M, Butler C, Hood K. Developing a new line of patter: can doctors change their consultations for sore throat? Med Educ 2002;36(7):678-81.

9. Rethans JJ, Norcini JJ, Baron Maldonado M, Blackmore D, Jolly BC, LaDuca T et al. The relationship between competence and performance: implications for assessing practice performance. Med Educ 2002;36(10):901-9.

10. Cals JW, Hopstaken RM, Butler CC, Hood K, Severens JL, Dinant GJ. Improving management of patients with acute cough by C-reactive protein point of care testing and communication training (IMPAC3T): study protocol of a cluster randomised controlled trial. BMC Fam Pract 2007;8:15.

11. Butler CC, Kinnersley P, Prout H, Rollnick S, Edwards A, Elwyn G. Antibiotics and shared decision-making in primary care. J Antimicrob Chemother 2001;48(3):435-40.

12. Rollnick S, Mason P, Butler C. Health Behavior Change; a guide for practitioners: Churchill Livingston; 1999.

13. Cals JW, Scheppers NA, Hopstaken RM, Hood K, Dinant GJ, Goettsch $\mathrm{H}$ et al. Evidence based management of acute bronchitis; sustained competence of enhanced communication skills acquisition in general practice. Patient Educ Couns 2007;68(3):270-8.

14. Sanson Fisher R, Cockburn J. Effective teaching of communication skills for medical practice: selecting an appropriate clinical context. Med Educ 1997;31(1):52-7.

15. Okkes IM, Oskam SK, Lamberts H. Van klacht naar diagnose: episodegegevens uit de huisartspraktijk. Bussum: Couthino; 1998. [From complaint to diagnosis: Disease episodes in general practice. Bussum: Couthino; 1998].

16. Coenen S, Michiels B, Royen P van, Auwera JC vader, Denekens J. Antibiotics for coughing in general practice: a questionnaire study to quantify and condense the reasons for prescribing. BMC Fam Pract 2002;3(1):16.

17. Aspegren K. BEME Guide No.2: Teaching and learning communication skills in medicine - a review with quality grading of articles. Med Teach 1999;21(6):563-70. 
18. Levinson W, Roter D. The effects of two continuing medical education programs on communication skills of practicing primary care physicians. J Gen Intern Med 1993;8(6):318-24.

19. Kramer AW, Dusman H, Tan LH, Jansen JJ, Grol RP, Vleuten CP van der. Acquisition of communication skills in postgraduate training for general practice. Med Educ 2004;38(2):158-67.

20. Maiburg BHJ, Rethans J-JE, Erk IM van, MathusVliegen LMH, Ree JW van. Fielding incognito standardised patients as 'known' patients in a controlled trial in general practice. Med Educ 2004;38(12):1229-35.

De auteurs:

Drs. Jochen W.L. Cals is huisarts in opleiding en onderzoeker.*

Mw. drs. Nicole A.M. Scheppers is longarts in opleiding, Atrium Medisch Centrum Parkstad Heerlen.

Prof. dr. Geert-Jan Dinant is huisarts en hoogleraar

huisartsgeneeskunde. *

Drs. Henk Goettsch is gedragswetenschapper.*
Prof. dr. Rogier Hopstaken is huisarts en onderzoeker, Vakgroep Huisartsgeneeskunde, School for Primary Care and Public Health (CAPHRI), Universiteit Maastricht en Stichting Gezondheidscentra Eindhoven.

Mw. dr. K. Hood is statisticus, South East Wales Trials Unit, School of Medicine, Cardiff University, Wales.

Prof. Chisthopher Butler is huisarts en hoogleraar huisartsgeneeskunde, Department of Primary Care and Public Health, School of Medicine, Cardiff University, Wales.

* Allen zijn verbonden aan de vakgroep Huisartsgeneeskunde, School for Primary Care and Public Health (CAPHRI), Universiteit Maastricht.

Correspondentieadres:

Drs. J.W.L. Cals, Vakgroep Huisartsgeneeskunde, Universiteit Maastricht, Postbus 616, 6200 MD Maastricht. Tel.:043-3882441; e-mail: j.cals@hag.unimaas.nl

Belangenconflict: geen gemeld.

Financiële ondersteuning: Deze studie werd gesubsidieerd door Zon MW Doelmatigheidsonderzoek.

\section{Summary}

Objective: To investigate if a training programme of communication skills in consultations about lower airway infection for general practitioners including context-rich learning experiences and peer review of consultation transcripts results in the acquisition and retention of enhanced communication skills while preserving adequate time management of consultations.

Methods: A pre-test - post-test study among 20 general practitioners evaluated whether a communication skills programme resulted in enhanced communication skills. Consultations with simulated patients in routine practice were audiotaped before and within two weeks and 6 months after attendance of communication skills training. The audiotaped consultations were analysed and the duration was measured. Transcripts were scored on specific skills to determine the short-term and long-term effects of training on the general practitioners' communication skills.

Results: The results show that the GPs acquired key communication skills and retained these during 6 months. The duration of the consultations remained within normal range for primary care.

Discussion and conclusion: Specific communication skills for acute bronchitis can be successfully acquired by GPS through context-rich communication training with peer review of transcripts of consultations with simulated patients, without making consultation length unfeasible. This approach appears to be useful for enhancing communication skills competence in general practice. (Cals JWL, Scheppers NAM, Hopstaken RM, Hood K, Dinant G-J, Goettsch H, Butler CC. Context-related communication skills training for general practice consultations about lower airway infections. Dutch Journal of Medical Education 2008;27(3):137-146.) 